\title{
EVOLUÇÃO DO DIREITO CONSTITUCIONAL DA CIDADANIA BRASILEIRA
}

Márcio Alexandre da Silva Pinto*

Sumário: 1 Introdução ao Direito Constitucional da Cidadania; 2 Evolução do Direito Constitucional da Cidadania Brasileira; 3 Direito Constitucional da Cidadania Brasileira na Constituição de 1824; 4 Direito Constitucional da Cidadania Brasileira na Constituição de 1891; 5 Direito Constitucional da Cidadania Brasileira na Constituição de 1934; 6 Direito Constitucional da Cidadania Brasileira na Constituição de 1937; 7 Direito Constitucional da Cidadania Brasileira na Constituição de 1946; 8 Direito Constitucional da Cidadania Brasileira na Constituição de 1967; 9 Direito Constitucional da Cidadania Brasileira na Constituição de 1969; 10 Conclusões finais.

Resumo: Antes de 1824, não há que se falar em Cidadania Brasileira ${ }^{1}$, visto que o Brasil era colônia de Portugal, sem autonomia administrativa, política e social, não tinha território, nem povo (Cidadania), propriamente. Com a Proclamação da Independência do Brasil em 1822, mais especialmente, pela Constituição de 1824, iniciado o Direito Constitucional da Cidadania Brasileira, que "evoluiu” através das demais Constituições de: 1891, 1930, 1934, 1946, 1967 e de 1969, conforme apresentado neste estudo abaixo. A evolução na atual Constituição Brasileira de 1988 será aprofundada noutro trabalho.

Palavras-chave: Cidadania. Constitucional. Direito.

Ex-Diretor e Professor da FaDir-UFU. Mestre e Doutor em Direito da Cidadania, pela PUC/SP.

1 Cidadania como um substantivo coletivo, no sentido subjetivo, por exemplo, a Cidadania Brasileira. 


\section{Introdução ao Direito Constitucional da Cidadania}

Antes mesmo da evolução do Direito Constitucional da Cidadania Brasileira, faz-se necessária apresentar a evolução deste novo ramo do Direito, o que se faz nesta introdução, a partir das conclusões de outro trabalho publicado ${ }^{2}$, como aprofundamento da referida Tese de Doutorado.

Durante a Antigüidade primitiva mais remota, como o Homem vivia no estado natural, tanto os deveres quanto os direitos comuns, enfim, o então Direito Público, era igual para todos, regulado pelas leis da natureza. Nesta época, não havia uma organização de proteção do Homem, prevalecia a força bruta. Os doutrinadores do direito denominam esta fase de período da autodefesa, em que cada um protegia seu suposto direito pela força bruta pessoal.

Anterior ao surgimento das cidades, na Antigüidade primitiva, em especial das chamadas cidades-Estados, predominava o estabelecimento de deveres sobre os direitos, como providência divina, sendo as pessoas desta época consideradas filhos do Senhor, alguém, ninguém, coisa, sem qualquer concepção de cidadania. Assim, o Direito Público Primitivo caracterizava-se pela imposição de deveres à maioria daquela sociedade, com a garantia de alguns direitos (privilégios), apenas a uma minoria.

Na Antigüidade clássica, com o surgimento das cidades-Estados, que deram origem e conteúdo objetivo ao termo cidadania, esta era concebida como um "status" privilegiado de alguns, homens livres, de participar das decisões de interesse público. Assim, cidadão era aquele homem livre, adulto, possuidor de bens de valor, por isso, inscrito no censo, que tinha o direito de participar das deliberações e da jurisdição pública, enfim, tinha direitos (privilégios) políticos. Desse modo, no Estado Antigo Clássico, o Direito Público consistia nas normas de imposição de deveres a todos, com a garantia de direitos de natureza política a alguns homens livres considerados cidadãos.

A Concepção Antiga de Direito Público, consistente na garantia de direitos (privilégios) políticos apenas a uma minoria da sociedade, praticamente manteve durante toda a Idade Média, salvo alguns retrocessos, com ampliação apenas do território estatal pelo surgimento dos Impérios, destacando-se o Império Romano que ainda continuou por muito

2 SILVA PINTO, Márcio Alexandre da. Evolução do Direito Público da Cidadania. Revista da Faculdade de Direito da Universidade Federal de Uberlândia, Uberlândia, v. 34, p. 201-250, dez. 2006 
tempo apenas a declarar o direito, cabendo a cada um a sua defesa pessoal, embora impondo deveres a todos da sociedade.

Com o advento da Revolução Francesa e outros acontecimentos históricos importantes do final do século XVIII, o Direito Público da Cidadania passou a ser concebido como o direito de participar das decisões de interesse público (direitos políticos), com ampliação de seus titulares, através das eleições, malgrado ainda limitado por alguns requisitos, especialmente o econômico. Desse modo, cidadão passou a ser aquele que, estando inscrito no órgão eleitoral, possuía direitos políticos de participar das eleições, com alguns direitos civis, como a liberdade de ir e vir, de contratar e de defender, através do Estado, único titular do Direito Público nesta época.

Pela Concepção Moderna de Direito Público da Cidadania apenas devem ser considerados cidadãos os eleitores inscritos no órgão eleitoral, admitindo a mulher maior de idade como cidadã, sendo os demais considerados apenas indivíduos nacionais. Nesse sentido, cidadania é substituída pelo conceito de nacionalidade, como qualidade que gera apenas direitos civis e políticos. De acordo com a Teoria Liberal do Direito, apenas o Estado é titular de direito público, passando a considerar o seu membro como indivíduo, titular apenas de direitos individuais e privados.

Pela Concepção Contemporânea (Cidadã) de Direito da Cidadania, cidadãos são todos os membros da nação, natos ou naturalizados, com iguais deveres e direitos, tanto políticos, quanto civis, como sociais, incluindo nestes os econômicos, os culturais e os de solidariedade, conforme estabelecido democraticamente em lei. Cidadania adquire duplo sentido, objetivamente, significa a qualidade de membro do Estado, que tem mútuos deveres e direitos civis, políticos e sociais, subjetivamente, refere-se ao conjunto de cidadão, como substantivo coletivo de cidadão, como por exemplo, a Cidadania Brasileira, a Cidadania Francesa, a Cidadania Portuguesa.

Pela Concepção Contemporânea (Cidadã) de Direito Público, cidadãos(ãs) são todos os membros da nação, natos ou naturalizados, com iguais deveres e direitos, tanto políticos, quanto civis, como sociais, incluindo nestes os econômicos, os culturais e os de solidariedade, conforme estabelecidos democraticamente em lei.

Este novo ramo do Direito, consubstanciado nos deveres e direitos de todos enquanto cidadãos(ãs), incluindo além dos direitos políticos, os direitos civis e os direitos sociais, atualmente deve ser denominado de Direito Público da Cidadania. 
Em conclusão inicial, o Direito Público da Cidadania é o gênero da Ciência do Direito, que tem por objeto as normas jurídicas de proteção dos cidadãos, disciplinando seus deveres e direitos civis, políticos e sociais, com os seus respectivos instrumentos de defesa e garantia, que constituídos, compõem o Direito Constitucional da Cidadania.

\section{Evolução do Direito Constitucional da Cidadania Brasileira}

Como é sabido, o Brasil teria sido descoberto em 1500 d. C., pelos Portugueses, que passaram a colonizar o país, situação esta que perdurou até o ano de 1822, quando da Proclamação da Independência, precisamente, até a Constituição de 1824, quando o Estado brasileiro foi constituído, com Cidadania (Povo), Território e Governo próprios.

Desse modo, até 1824, o Brasil foi colônia de Portugal, sem qualquer autonomia administrativa, política e social, sem território e cidadãos próprios (independentes). Portanto, até esta data, não há que se falar em Direito Constitucional da Cidadania Brasileira, visto que não existia de fato e direito a Cidadania, nem o Estado Brasileiro.

Neste período, predominava a população analfabeta, uma sociedade escravista, uma economia de monocultura e latifundiária, com um estado policial e fiscalizador, conforme José Murilo de Carvalho, que aduz ainda: “Al final de la colónia no había ni ciudadanos brasileños ni pátria brasileña"3.

Diferentemente das outras colônias americanas, nas palavras do autor acima mencionado, "na colônia portuguesa da América não há concomitância entre a organização do Estado e a formação da nação: a presença do Estado precede, no Brasil, a formação de qualquer sentimento nacional"4.

Destarte, durante o período em que o Brasil foi colônia de Portugal, realmente não há o que se falar em Direito Constitucional da Cidadania Brasileira, porquanto não havia Cidadania nem Pátria brasileira, mesmo porque, esta pressupõe a existência do Estado-Nação, com território, governo e povo (cidadãos) próprios, o que somente ocorreu com a Proclamação da Independência em 1822, mais especialmente, em 1824, com a primeira Constituição Brasileira.

3 CARVAlHO, José Murilo de. Desenvolvimiento de la ciudadanía en Brasil. Ciudad de México: Fondo de Cultura Económica, 1995, p. 15.

4 QUIRINO, Célia Galvão; MONTES, Maria Lúcia. Constituições brasileiras e cidadania. São Paulo: Ática, 1987, p. 36. 


\section{Direito Constitucional da Cidadania Brasileira na Constituição de 1824}

Como acima mencionado, antes de se examinar os Direitos da Cidadania na Constituição Brasileira de 1824, necessário investigar a concepção de cidadania por esta adotada, analisando quem esta considerava cidadão(ã) brasileiro(a), para depois, analisar os seus deveres e direitos, enfim, o Direito da Cidadania Brasileira nesta época.

Preliminarmente, importante destacar que a referida Constituição Brasileira, define a Cidadania Brasileira logo no seu Título 2ª que nomeia "Dos Cidadãos Brazileiros", demonstrando assim uma valorização desta qualidade, colocando-a logo no início, como pressuposto da Organização do Estado Brasileiro.

A propósito, nos termos do artigo $6^{\circ}$, da mencionada Constituição Brasileira de 1824 , eram considerados Cidadãos Brasileiros:

I. Os que no Brazil tiverem nascido, quer sejam ingênuos, ou libertos, ainda que o pai seja estrangeiro, uma vez que este não resida por serviço de sua Nação.

II. Os filhos de pai Brazileiro, e os illegitimos de mãe Brazileira, nascidos em paiz estrangeiro, que vierem estabelecer domicilio no Império.

III. Os filhos de pai Brazileiro, que estivesse em paiz estrangeiro em serviço do Império, embora elles não venham estabelecer domicilio no Brazil.

IV. Todos os nascidos em Portugal, e suas Possessões, que sendo já residentes no Brazil na época, em que se proclamou a Independência nas províncias, onde habitavam, adheriram à esta expressa, ou tacitamente pela continuação da sua residência.

V. Os estrangeiros naturalizados, qualquer que seja a sua Religião. A lei determinará as qualidades precisas, para se obter Carta de Naturalização. ${ }^{5}$

Assim, na Constituição Brasileira de 1824, observa-se uma exaltação da qualidade de cidadão, malgrado refletindo ainda a concepção antiga de cidadania, porquanto esta somente considerava "Cidadãos Brasileiros" os homens livres, nascidos no Brasil ou no estrangeiro, filhos de Brasileiros, com residência ou domicílio no Brasil, bem como os naturalizados na forma da lei, com exclusão das mulheres, das crianças e dos escravos.

Os direitos da Cidadania Brasileira na Constituição de 1824 estão protegidos somente no seu último Título e junto com as disposições gerais, demonstrando assim uma

5 CAMPanhole, Adriano; CAMPANHOle, Hilton Lobo. Constituições do Brasil. 4. ed. São Paulo: Atlas, 1986, p. 655-656. 
desvalorização destes direitos dos cidadãos, todavia, dispondo, literalmente, sobre Direitos Civis e Políticos dos Cidadãos. ${ }^{6}$

6 A propósito, assim constituídos os Direitos da Cidadania Brasileira: “Art. 179. A inviolabilidade dos Direitos Civis e Políticos dos Cidadãos Brasileiros, que tem por base a liberdade, a segurança individual, e a propriedade, é garantida pela Constituição do Império, pela maneira seguinte:

I - Nenhum Cidadão pode ser obrigado a fazer, ou deixar de fazer alguma cousa, senão em virtude da Lei.

II - Nenhuma Lei será estabelecida sem utilidade publica.

III - A sua disposição não terá efeito retroactivo.

IV - Todos podem comunicar os seus pensamentos, por palavras, escriptos, e publicá-los pela Imprensa, sem dependência de censura; com tanto que hajam de responder pelos abusos, que commetterem no exercício deste Direito, nos casos, e pela forma, que a Lei determinar.

V - Ninguém póde ser perseguido por motivo de Religião, uma vez que respeite a do Estado, e não offenda a Moral Publica.

VI - Qualquer póde conservar-se, ou sair do Império, como lhe convenha, levando consigo os seus bens, guardados os Regulamentos policiais, e salvo o prejuízo de terceiro.

VII - Todo o Cidadão tem em sua casa um asylo inviolável. De noite não se poderá entrar nella, senão por seu consentimento, ou para o defender de incendio, ou inundação; e de dia só será franqueada a sua entrada nos casos, e pela maneiro, que, a Lei determinar.

VIII - Ninguém poderá ser preso sem culpa formada, excepto nos casos declarados na Lei; e nestes dentro de vinte e quatro horas contadas da entrada na prisão, sendo em Cidades, Villas, ou outras povoações próximas aos lugares da residência do Juiz; e nos lugares remotos dentro de um prazo razoável, que a Lei marcará, attenta a extensão do território, o Juiz por uma Nota, por elle assignada, fará constar ao Réo o motivo da prisão, os nomes do seu accusador, e os da testemunhas, havendo-as.

IX - Ainda com culpa formada, ninguem será conduzido à prisão, ou nella conservado estando já preso, se prestar fiança idonea, nos casos, que a Lei a admitte: e em geral nos crimes, que não tiverem maior pena, do que a de seis mezes de prisão, ou desterro para fóra da Comarca, poderá o Réo livrar-se solto.

X - Á excepção de flagrante delicto, a prisão não póde ser executada, senão por ordem escripta da Autoridade legitima. Se esta fôr arbitraria, o Juiz, que a deu, e quem a tiver requerido serão punidos com as penas, que a Lei determinar. O que fica disposto acerca da prisão antes de culpa formada, não comprehende as Ordenanças de Militares, estabelecidas como necessarias á disciplina, e recrutamento do Exercito; nem os casos, que não são puramente criminaes, e em que a Lei determina todavia a prisão de alguma pessoa, por desobedecer aos mandados da Justiça, ou não cumprir alguma obrigação dentro de determinado prazo.

XI - Ninguem será sentenciado, senão pela Autoridade competente, por virtude de Lei anterior, e na fórma por Ella prescripta.

XII - Será mantida a independência do Poder Judicial. Nenhuma Autoridade poderá avocar as Causas pendendes, susta-las, ou fazer reviver os processos findos.

XIII - A lei será igual para todos, quer proteja ou castigue, e recompensará em proporção dos merecimentos de cada um.

XIV - Todo o Cidadão pode ser admittido aos Cargos Públicos Civis, Políticos, ou Militares, sem outra diferença, que não seja a dos seus talentos, e virtudes.

$\mathrm{XV}$ - Ninguem será exempto de contribuir para as despesas do Estado em proporção dos seus haveres.

XVI - Ficam abolidos todos os Privilegios, que não forem essencial, e inteiramente ligados aos Cargos, por utilidade pública.

XVII - A excepção das Causas, que por sua natureza pertencem a Juizos, particulares, na conformidade das Leis, não haverá foro privilegiado, nem Comissões especiaes nas Causas civeis, ou crimes.

XVIII - Organizar-se-á quanto antes um Código Civil, e Criminal, fundado nas solidas bases da Justiça, e Eqüidade.

XIX - Desde já ficam abolidos os açoites, a tortura, a marca de ferro quente, e todas as mais penas cruéis.

XX - Nenhuma pena passará da pessoa do delinqüente. Por tanto não haverá em caso algum confiscação de bens, nem a infâmia do Réu se transmitirá aos parentes em qualquer gráo, que seja.

XXI - As Cadêas serão seguras, limpas, e bem arejadas, havendo diversas casas para separação dos Réos, conforme suas circunstancias, e natureza dos seus crimes.

XXII - É garantido o Direito de Propriedade em toda a sua plenitude. Se o bem público legalmente verificado exigir o usos, e emprego da Propriedade do Cidadão, será elle préviamente indemnisado do valor della. A Lei marcará os casos, em que terá logar esta unida excepção, e dará as regras para se determinar a indeminisação. XXIII - Também fica garantida a Divida Publica. 
Neste particular, importante destacar que, nos termos do artigo $7^{\circ}$, da referida Constituição Brasileira, os Direitos de Cidadão Brasileiro podiam ser perdidos. Com efeito, pelo artigo $8^{\circ}$, o exercício dos Direitos Políticos podiam ser suspensos. ${ }^{7}$

Desse modo, os direitos de(a) cidadania na Constituição Brasileira de 1824, já refletindo a concepção moderna dos direitos de(a) cidadania, consistiam em Direitos Civis e Direitos Políticos. Os Direitos Civis eram garantidos a todos os considerados Cidadãos Brasileiros, que embora podendo serem perdidos, sem maiores limitações. Todavia, o exercício dos Direitos Políticos, mesmo entre os considerados Cidadãos Brasileiros, sofriam grandes restrições quanto ao sexo, à idade, até quanto aos bens, inclusive podendo serem suspensos, como demonstrado.

Outrossim, quanto à defesa dos direitos de(a) cidadania, refletindo a concepção dominante à época, cabia ao próprio indivíduo através do Estado, realizar sua defesa. O direito de defesa era associado basicamente ao processo judicial sobretudo na área penal e sempre inserido no rol dos direitos e garantias individuais. A Carta Básica do Império,

XXIV - Nenhum genero de trabalho, de cultura, industria, ou compercio póde ser prohibido, uma vez que não se opponha aos costumes publicos, á segurança, e saude dos Cidadãos.

XXV - Ficam abolidas as Corporações de Officios, seus Juizes, Escrivães, e Mestres.

XXVI - Os inventores terão a propriedade das suas descobertas, ou das suas produções. A lei lhes assegurará um privilégio exclusivo temporário, ou lhes remunerará em ressarcimento da perda, que hajam de sofrer pela vulgarização.

XXVII - O Segredo das Cartas é inviolavel. A administração do Correio fica rigorosamente responsável por qualquer infracção deste Artigo.

XXVIII - Ficam garantidas as recompensas conferidas pelos serviços feitos ao Estado, quer Civis, quer Militares; assim como o direito adquirido a ellas na fórma das Leis.

XXIX - Os Empregados Publicos são estrictamente responsáveis pelos abusos, e omissões praticadas no exercício das suas funcções, e por não fazerem efetivamente responsáveis aos seus subalternos.

XXX - Todo o cidadão poderá apresentar por escripto ao Poder Legislativo, e ao Executivo reclamações, queixas, ou petições, e até expôr qualquer infracção da Constituição, requerendo perante a competente Autoridade a effectiva responsabilidade dos infractores.

XXXI - A Constituição também garante os socorros publicos.

XXXII - A Instrução primaria, é gratuita a todos os Cidadãos.

XXXIII - Collegios, e Universidades, aonde serão ensinados os elementos da Sciencias, Bellas Letras, e Artes.

XXXIV - Nos casos de rebelião, ou invasão de inimigos, pedindo segurança do Estado, que se dispensem por tempo determinado algumas das formalidades, que garantem a liberdade individual, poder-se-ha fazer for acto especial do Poder Legislativo. Não se achando porém a esse tempo reunida a Assembléia, e correndo a Patria perigo imminente, poderá o Governo responsavel, suspendendo-a immediatamente que cesse a necessidade urgente, que a motivou; devendo num, e outro caso remetter á Assembléia, logo que reunida fôr, uma relação motivada das prisões, e d’outras medidas de prevenção tomadas; e quaesquer Autoridades, que tiverem mandado proceder a ellas, serão responsáveis pelos abusos, que tiverem praticado a esse respeito." CAMPANHOLE, Adriano; CAMPANHOLE, Hilton Lobo. Constituições do Brasil. 4. ed. São Paulo: Atlas, 1986, p. 674-676.

7 Nos termos do artigo $7^{\circ}$, da Constituição Brasileira de 1824, perdia-se os Direitos de Cidadão Brasileiro: "I. $\mathrm{O}$ que se naturalizar em paiz estrangeiro. II. O que sem licença do Imperador aceitar Emprego, Pensão, ou Condecoração de qualquer Governo Estrangeiro. III. O que for banido por Sentença." De acordo com o artigo $8^{\circ}$, supendia-se o exercício dos Direitos Políticos: "I. Por incapacidade physica ou moral. II. Por Sentença condenatória a prisão, ou degredo, enquanto durarem os seus efeitos". CAMPANHOLE, Adriano; CAMPANHOLE, Hilton Lobo. Constituições do Brasil. 4. ed. São Paulo: Atlas, 1986, p. 656. 
embora não se referisse literalmente ao direito à defesa, impunha ao juiz que fizesse constar ao réu "o motivo da prisão, o nome do seu acusador e os das testemunhas, havendo-as", na hipótese de prisão, sem culpa formada, que admitia pudesse ocorrer como exceção, "nos casados declarados em lei (art. 179, § 8)"8.

Com efeito, quando da independência do Brasil, aqui continuaram a viger as legislações portuguesas, mais especialmente, na área processual, que vigorava as normas processuais das Ordenações Filipinas, também denominadas Ordenações do Reino, desde que não contrariassem a soberania brasileira. ${ }^{9}$ O processo era escrito e desenvolvia-se por fases, paralisando ao fim de cada uma delas e se desenrolava por exclusiva iniciativa das partes, ${ }^{10} \mathrm{o}$ que denota a adoção da antiga concepção autodefensiva de auto-proteção, pela própria Cidadania Brasileira.

\section{Direito Constitucional da Cidadania Brasileira na Constituição de 1891}

A Constituição Brasileira de 1891, com maior objetividade na sua redação, embora declarado em 1888, o fim da escravidão, praticamente, mantém a mesma concepção de cidadania consagrada na de 1824, com alguma modificação não de conteúdo, mas importante para este estudo.

Na Constituição Brasileira de 1891, em primeiro lugar, destaca-se a Organização do Estado Brasileiro, sob a forma de República, com menção da Cidadania Brasileira, definindo quais eram considerados Cidadãos Brasileiros, somente no "Título IV - Dos Cidadãos Brazileiros", demonstrando assim uma certa desvalorização desta qualidade de membro da nação.

Quanto aos direitos de(a) cidadania na Constituição de 1891, como infere-se do seu artigo 72, constata-se também que, praticamente, foram mantidos os mesmos direitos garantidos na Constituição de 1824, malgrado colocados na forma de Declaração de Direitos dos Brasileiros e não mais dos Cidadãos Brasileiros.

8 PEREIRA JUNIOR, Jessé Torres. O direito à defesa na Constituição de 1988. Rio de Janeiro: Renovar, 1991.

9 SILVA PINTO, Márcio Alexandre da. Evolução Histórica do Direito Processual. 1991. Trabalho de Conclusão de Curso (Especialização)-Universidade Federal de Uberlândia, Uberlândia, 1991, p. 16.

10 THEODORO JÚNIOR, Humberto. Curso de Direito Processual Civil. Rio de Janeiro: Forense, 1990 , p. 14. 
Por outro lado, observa-se que já não mais se menciona a divisão literal dos direitos dos Cidadãos Brasileiros em Direitos Civis e Direitos Políticos, como feito na Carta Magna anterior, representando assim esvaziamento do conceito de cidadania, certamente acompanhando doutrina incipiente que advogava que estes restringiriam apenas aos direitos políticos e cidadãos eram apenas os inscritos no órgão eleitoral, sendo os direitos civis e sociais, respectivamente, direitos individuais e coletivos.

Com referência aos direitos políticos na Constituição Brasileira de 1891, observa-se uma ampliação de seus titulares, pela redução para 21 anos para ser considerado eleitor (artigo 70), malgrado mantida a exclusão das mulheres, dos mendigos, dos analfabetos, dos soldados e dos religiosos de forma geral.

Neste particular, importante observar ainda que a referida Constituição Brasileira acabou com o voto censitário do Império, embora excluídos os mendigos, bem como, com o sistema indireto de escolha dos representantes ao Legislativo, representando um avanço do ponto de vista dos direitos políticos da cidadania.

A propósito, o direito de voto era concedido a todos os cidadãos brasileiros, respeitadas as seguintes limitações:

que sejam do sexo masculino, maiores de 21 anos, alfabetizados, e que não se encontrem na condição de mendigos, praças de pré (sic) - excetuando-se os alunos das escolas militares de ensino superior ou religiosos de ordens monásticas, companhias, congregações ou comunidades de qualquer denominação, sujeitas a voto de obediência, regra ou estatuto que importe a renúncia da liberdade individual. ${ }^{11}$

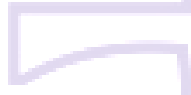

Realmente, observa-se assim uma ampliação dos direitos políticos da cidadania brasileira, acabando com o voto censitário e o sistema indireto, malgrado ainda com grande exclusão.

Por outro lado, com o fim da escravidão em 1888, observa-se uma ampliação da Cidadania Brasileira, pela maior participação dos antigos escravos, especialmente com relação aos direitos civis, considerando que a maioria era composta por analfabetos, malgrado continuando excluídos dos direitos políticos.

11 QUIRINO, Célia Galvão; MONTES, Maria Lúcia. Constituições brasileiras e cidadania. São Paulo: Ática, 1987 , p. 52 
Nesse sentido, importante destacar que com a proclamação da República observa-se ainda uma grande valorização do cidadão como membro soberano da nação brasileira, ao ponto do Marechal Deodoro da Fonseca, líder do governo provisório, proclamar aos “concidadãos" que a principal missão deste era garantir com a ordem pública, a liberdade e os direitos da Cidadania Brasileira. ${ }^{12}$

Assim, os direitos de(a) cidadania na Constituição Brasileira de 1891, refletindo ainda a concepção moderna de cidadania, resumiram-se em direitos civis e direitos políticos, na forma de declaração, com ampliação de seus titulares, especialmente, pelo fím da escravidão, pela redução para 21 anos para ser eleitor, fim do voto censitário e indireto, apesar da exclusão das mulheres, dos mendigos, dos analfabetos e dos religiosos de forma geral.

Do ponto de vista instrumental, a Cidadania Brasileira gozava de uma certa liberdade de se manifestar, malgrado limitada pela própria cultura, com a instituição de alguns instrumentos judiciais de defesa dos direitos fundamentais.

Com a implantação da República em 1891, foi estabelecido a dicotomia entre a Justiça Federal e a Estadual. Com efeito, pela Constituição de 1891, a competência para legislar sobre normas de processo foi transferida para os Estados Membros. Foi elaborado um Código da União e alguns Códigos Estaduais, ressaltando o da Bahia e o de São Paulo. ${ }^{13}$ Em alguns Estados continuaram a serem aplicadas as disposições do Regulamento $737^{14}$, vez que nem todos conseguiram elaborar o seu Código de Processo Civil. A Emenda de 1926 garantiu plena defesa aos acusados (art. 72, § 16).

Destarte, pouco desenvolvimento do direito processual civil foi observado neste período, haja vista que os Estados que conseguiram elaborar seu Código de Processo, em sua maioria, copiaram o Código Federal ou da União. Apenas no Código da Bahia e no de São Paulo se notou algumas inovações inspiradas no moderno direito europeu ${ }^{15}$, malgrado individualista, centrado na parte como indivíduo e não como cidadão.

12 CAMPANHOle, Adriano; CAMPANHOLE, Hilton Lobo. Constituições do Brasil. 4. ed. São Paulo: Atlas, 1986, p. 624.

13 SANTOS, Ernane Fidélis. Manual de Direito Processual Civil. 15. ed. São Paulo: Saraiva, 2011. v. 1. p. 3.

14 Cf. Autorac. cit., p. 7, o Regulamento 737, representou o primeiro Código Processual Brasileiro, que, no início, se destinou apenas a regular o processamento das causas comerciais. Em 1890 foi editado o Regulamento 763, que estendeu a sua aplicação às causas civis. Em 1876, foram reunidas todas as normas processuais civis e um corpo único, que foi denominada de Consolidação de Ribas, em homenagem ao seu Autor, o ilustre Prof. Antônio Joaquim Ribas.

15 THEODORO JÚNIOR, Humberto. Curso de Direito Processual Civil. Rio de Janeiro: Forense, 1990, p. 37. 


\section{Direito Constitucional da Cidadania Brasileira na Constituição de 1934}

Na Constituição Brasileira de 1934, observa-se um esvaziamento total da qualidade de cidadão, ao ponto de não se definir mais "Cidadãos Brasileiros", como observado nas Constituições Brasileiras anteriores, passando adotar concepção de nacionalidade em vez de cidadania, acompanhando doutrina dominante à época.

Por outro lado, constata-se uma exaltação da Organização do Estado, que ocupa os primeiros capítulos da referida Constituição, para somente depois mencionar, na forma de Declaração de Direitos, os direitos políticos (art. 106) e os direitos e garantias individuais (art. 113).

Em vez de definir quem seria considerado cidadão(ã) brasileiro(a), com vínculo jurídico e político perante a nação, assumindo deveres e consequentemente direitos de(a) cidadania, a referida Carta Magna apenas definia quem era considerado brasileiro (art. 106), exaltando tão somente o vínculo territorial (nacionalidade), acompanhando doutrina constitucional dominante na época.

Tanto é verdade que no próximo artigo (art. 107), quando nas Cartas Magnas anteriores referia-se aos direitos de(a) cidadania, a referida Constituição Brasileira definia quando se perdia a nacionalidade brasileira, mantendo praticamente as mesmas situações previstas anteriormente para perda daqueles.

Quanto aos direitos políticos observa-se uma nova ampliação, pela inclusão das mulheres como eleitoras e a redução para 18 anos para se alistar, contudo continuando excluídos do alistamento os eleitores que não sabiam ler e escrever, os soldados de forma geral, os mendigos e os que estivessem privados de seus direitos políticos, conforme infere-se do artigo 108, da discutida Constituição Brasileira.

Com relação aos direitos civis, também acompanhando doutrina dominante, que digase de passagem, contribuiu para o restringimento dos direitos de(a) cidadania apenas aos direitos políticos, a referida Constituição Brasileira de 1934, sob a forma de direitos e garantias individuais, também, praticamente, garantiu os mesmos direitos de caráter civil consagrados pelas Cartas Magnas anteriores.

Na referida Constituição, diferentemente das anteriores, refletindo concepção trazida pelos movimentos sociais do final do século passado e início do corrente, relacionados com a 
questão social, observa-se a proteção de uma nova categoria de direitos de natureza social, como a liberdade sindical (art. 120), o direito do trabalho (art. 121) e o direito à educação (art. 149), malgrado sem qualquer concepção como direito de(a) cidadania.

Desse modo, na Constituição Brasileira de 1934 observa-se um esvaziamento do conceito de cidadania, substituindo-o pelo de nacionalidade, com os direitos de(a) cidadania garantidos na forma de declaração, com igual consagração dos direitos políticos e dos direitos e garantias individuais feitos pelas Cartas Magnas anteriores, com incipiente garantia de direitos sociais, com efeito, também sem qualquer concepção de direito de(a) cidadania.

Todavia, pela Constituição de 1934, consoante ao processo como meio de defesa através do Estado, esta retirou dos Estados Membros da Federação, a competência para legislar sobre o direito processual civil. Também, garantido a plena defesa, ora denominada de "ampla defesa" (art. 113, § 24), aos acusados, perante o Judiciário. ${ }^{16}$

\section{Direito Constitucional da Cidadania Brasileira na Constituição de 1937}

Na Constituição Brasileira de 1937, com efeito, também somente após a Organização do Estado, no capítulo nomeado "da Nacionalidade e da Cidadania", que se define quem são brasileiros, sem qualquer concepção de cidadania.

Quanto à definição de quem são brasileiros, a referida Constituição no seu artigo 115 , praticamente, repete a anterior, com exaltação apenas da nacionalidade, ou seja, do vínculo territorial.

Nesse sentido, no próximo artigo 116, igualmente à Carta Magna anterior, seguindo doutrina dominante, a Constituição Brasileira de 1937, prescreve as situações de perda da nacionalidade brasileira, no que também acompanha aquela.

Ao que parece, com efeito, acompanhando doutrina dominante, que considerava apenas os eleitores como cidadãos, no artigo 117 da discutida Constituição Brasileira, assim define quem possuía esta qualidade.

16 Cf. JUNIOR, Humberto Theodoro, ob. ac. cit., em atenção aos princípios da nova Carta Magna de 1934, o Governo nomeou uma comissão que foi composta por Artur Ribeiro, Carvalho Mourão e Levy Carneiro, para elaborarem um Código de Processo Civil Unitário, que, com efeito, não entrou em vigor, embora estivesse pronto o anteprojeto, porquanto ocorrera o golpe estadonovista. 
Neste particular, observa-se a manutenção do avanço consagrado na Carta Magna anterior, por considerar eleitores os brasileiros de ambos os sexos, maiores de dezoito anos, com exclusão do alistamento, os analfabetos, os militares em serviço ativo, os mendigos e os que estiverem privados dos seus direitos políticos.

A seguir, respectivamente, na referida Constituição Brasileira se previa quando se suspendiam (art. 118) e se perdiam (art. 119) os direitos políticos, que parecem aqui ser os únicos direitos considerados de(a) cidadania, na mesma linha da Carta Magna anterior, sem qualquer mudança substancial.

Destarte, pela referida Constituição de 1937, bem como, pela doutrina dominante da época, em nível crescente desta a Constituição do Império, percebe-se um esvaziamento do conceito de cidadania, com exaltação apenas da nacionalidade, restringindo os direitos de(a) cidadania aos direitos políticos, consequentemente, a concepção de que cidadãos seriam apenas os inscritos no alistamento eleitoral.

Em seguida, no capítulo que nomeia "Dos direitos e Garantias Individuais", mais especialmente no artigo 122, na discutida Constituição Brasileira de 1937, protegem-se os direitos civis, sem considerá-los direitos de(a) cidadania, mas apenas dos brasileiros e estrangeiros residentes no país.

Como na Carta Magna anterior tais direitos referiam-se à liberdade, à segurança individual e à propriedade, nos termos dos incisos do artigo mencionado, no que praticamente repete a declaração de direitos anterior, sem qualquer mudança substancial do ponto de vista da cidadania.

Malgrado sem qualquer concepção de cidadania, porquanto não se protegem aos seus titulares na condição de cidadão, na Constituição Brasileira de 1937 também se observam incipientes garantias com dimensão social, como as relacionadas com a família (arts. 124 a 127), educação e cultura (arts. 128 a 134), ordem econômica (arts. 135 a 155), neste particular, destacando a proteção ao trabalho, embora na condição apenas de trabalhador e não enquanto cidadão.

Com efeito, importante ressaltar ainda que a discutida Constituição Brasileira foi outorgada, com fechamento do Poder Legislativo Nacional e transferência de seus poderes ao Presidente da República de então (art. 180), demonstrando o nível de desvalorização da Cidadania Brasileira em que se chegou. 
Em síntese, os direitos da cidadania nesta Constituição Brasileira, resumiam-se aos Direitos Políticos, porquanto considerados cidadãos apenas os inscritos no alistamento eleitoral, que, diga-se de passagem, foram suspensos com a suspensão das eleições, com algumas garantias civis individuais e sociais, como hipossuficientes.

Pela Constituição de 1937, o Estado Brasileiro continua alheio à defesa própria dos direitos e interesses da Cidadania Brasileira. Apenas garante "as necessárias garantias de defesa", no termos do seu art. 122, $\S 11$, dentro de uma visão individual, cabendo ao próprio indivíduo e não enquanto cidadão realizar a sua defesa através do Estado Brasileiro, mais especialmente, do Poder Judiciário, nos limites da lei.

Quanto ao processo, a Constituição de 1937, manteve a unidade processual, ou seja, continuou a estabelecer a competência exclusiva da União para legislar sobre matéria processual. Logo após a sua promulgação, foi constituída uma comissão para elaborar um no anteprojeto de Código de Processo Civil.

Com efeito, das divergências verificadas entre os membros da Comissão, Pedro Batista Martins, com a ajuda de Guilherme Estelita, apresentou ao Governo o seu anteprojeto, que foi promulgado por meio do Decreto-Lei no $1.608 / 1939 .{ }^{17}$

De acordo com o Prof. Marcos Afonso Borges, o novo Código de Processo Civil Brasileiro não trouxe grandes inovações, a não ser a adoção dos princípios da publicidade, da oralidade, do dispositivo e o impulso oficial. Todavia, o Código manteve a sistemática até então vigente, no que pertine aos recursos, à execução, e aos procedimentos especiais. ${ }^{18}$

Desse modo, claro a opção constitucional pela doutrina do direito neoliberal, dado que a Constituição de 1937 foi outorgada sem a participação democrática da Cidadania Brasileira, com esvaziamento total do conceito de cidadania em função do instituto da nacionalidade, restringiu direitos, inclusive os próprios direitos políticos, somente garantindo alguns direitos individuais e coletivos, nos limites da lei.

17 BORGES, Marcos Afonso. Evolução histórica do Direito Processual Civil. Revista da Faculdade de Direito da Universidade Federal de Uberlândia, Uberlândia, v. 17, p. 257-292, dez. 1988, p. 289.

18 BORGES, Marcos Afonso. Evolução histórica do Direito Processual Civil. Revista da Faculdade de Direito da Universidade Federal de Uberlândia, Uberlândia, v. 17, p. 257-292, dez. 1988, p. 290. 


\section{Direito Constitucional da Cidadania Brasileira na Constituição de 1946}

Desde logo, observa-se que também a Constituição Brasileira de 1946, embora promulgada pelos representantes da Cidadania Brasileira, pejorativamente chamado ainda apenas de "povo", inicia-se pela Organização do Estado Brasileiro, como se este existisse antes daquela.

Com efeito, somente no Título IV, que nomeia "Da Declaração de Direitos", sem dizer de quem, em especial, no seu capítulo I, que junto com nacionalidade se menciona a cidadania, como observado na Carta Magna anterior.

Também, seguindo doutrina dominante nesse sentindo, não se define Cidadania Brasileira, definindo apenas o nacional (art. 129), praticamente repetindo também a Constituição anterior, sem qualquer alteração substancial do ponto de vista da concepção de proteção da Cidadania, refletindo ainda a concepção moderna, que considera cidadão apenas o inscrito no órgão eleitoral e os demais apenas indivíduos.

Igualmente, a seguir se estabelece as situações em que perdia a nacionalidade de brasileiro (art. 129), também, praticamente, repetindo a concepção anterior, com elevação do vínculo moral e territorial.

No artigo 131, define-se que são eleitores os brasileiros maiores de 18 anos, que se alistarem na forma da lei, praticamente mantendo o concebido pela Carta Magna anterior, sem literalmente garantir tal direito a ambos os sexos, como fez aquela.

Quanto à impossibilidade de alistar-se eleitores observa-se um avanço pela retirada do inciso que impedia os mendigos de se alistarem, consequentemente, concedendo-lhes os direitos políticos, mantendo no restante, praticamente, as mesmas concepções anteriores, considerando cidadão apenas os inscritos na Justiça eleitoral e os demais apenas como indivíduos, refletindo a concepção liberal de Estado.

Sobre as condições de suspensão ou perda dos direitos políticos, também, praticamente, nada se alterou com relação a Constituição anterior, mantendo-se as mesmas situações.

No capítulo II, que nomeia "Dos Direitos e das Garantias Individuais", ressalvando alguma ampliação dos direitos civis, também praticamente mantêm-se as declarações e 
consagrações anteriores, igualmente sem qualquer mudança substancial do ponto de vista dos direitos da Cidadania Brasileira.

No próximo capítulo, que nomeia "Da Ordem Econômica e Social”, também praticamente continuam os direitos e garantias protegidos anteriormente, com alguma ampliação, especialmente quando considera, por exemplo, a educação como direito de todos (art. 166), embora não se estabeleça como dever do Estado, representando algum avanço do ponto de vista dos direitos da Cidadania Brasileira.

Neste particular, importante destacar que o fato da referida Constituição Brasileira considerar a educação como direito de todos, inicia-se uma alteração na concepção antiga que restringia os direitos da Cidadania aos direitos políticos.

Em resumo, os direitos da Cidadania na Constituição Brasileira de 1946 continuam restritos aos direitos políticos, mantendo os direitos civis como garantias individuais, com alguma aplicação dos direitos sociais, embora considerando os seus titulares como indivíduo, pessoas hipossuficientes, e não enquanto cidadãos ou que tais direitos estão consagrados nesta condição.

Quanto à defesa da Cidadania Brasileira, não há praticamente alteração quanto à concepção anterior, garantindo "plena defesa" (art. 141, § 25) aos acusados, ainda que do ponto de vista formal, cabendo ao indivíduo a defesa do seu próprio direito, mantendo o Estado eqüidistante, decorrente do princípio processual do dispositivo.

\section{Direito Constitucional da Cidadania Brasileira na Constituição de 1967}

Também a Constituição Brasileira de 1967 inicia-se pela Organização do Estado Brasileiro, sem qualquer menção à Cidadania Brasileira, que é quem, a rigor, deveria fundamentar a criação deste (Estado), apenas mencionando o velho e conhecido "chavão", que todo poder emana do povo e em seu nome é exercido.

Em verdade, não apenas o poder emana ou deveria emanar da cidadania, estrategicamente denominada de povo, pelo consentimento de cada um na criação do Estado, no interesse comum de todos, mas também, como de fato ocorre, esta assume obrigações e deveres perante a nação, desde o nascimento. 
Com efeito, somente após a Organização do Estado, a referida Constituição, em Título que denomina "Da Declaração de Direitos", menciona os brasileiros, em capítulo I, que apenas nomeia "Da Nacionalidade", com exaltação, ao máximo, do vínculo territorial, com desprezo total pelo conceito de cidadania, que representa o vínculo político e jurídico de cada um perante a nação.

Neste ponto, quanto à definição de quem são considerados brasileiros, ressalvando a divisão em natos e naturalizados, seguindo doutrina dominante, também não se observa mudança substancial do ponto de vista da cidadania.

No capítulo II, nomeado "Dos Direitos Políticos”, destaca-se alteração reduzindo as impossibilidades do alistamento como eleitor, mantendo sem poderem alistar-se os analfabetos, os que não saibam exprimir-se na língua nacional e os privados dos direitos políticos, retirando-se os mendigos, que representava ainda resquício do voto censitário. Neste particular, constata-se ainda um avanço importante quando torna garantia constitucional o sufrágio universal e o voto direito e secreto (art. 143), com algumas exceções previstas na referida Constituição.

Com relação à suspensão e perda dos direitos políticos, constata-se uma ampliação das situações anteriores, com conseqüência da perda de mandato eletivo, com agravante de poder ser decretada pelo Presidente da República, em casos que menciona, posteriormente ampliada por emenda constitucional.

No capítulo IV, que apenas denomina "Dos Direitos e Garantias Individuais", a Constituição de 1967, praticamente mantém os mesmos direitos civis consagrados anteriormente, também sem qualquer mudança substancial do ponto de vista da concepção de cidadania anterior, seguindo a doutrina liberal dominante que considera cidadão apenas os inscritos no órgão eleitoral e os demais apenas indivíduos.

Também, quanto às garantias sociais, do ponto de vista da cidadania não se observa mudança substancial, porquanto, praticamente, mantêm-se os mesmos direitos protegidos na Carta Magna anterior, inclusive a educação como direito de todos (art. 168), mesmo porque, não considera os seus titulares enquanto cidadãos, mas como indivíduos hipossuficientes.

Com o recrudescimento do regime, conhecido como o da ditadura militar, através dos conhecidos atos institucionais, atos complementares, bem como, pelas Emendas Constitucionais a partir de 1969, várias alterações foram feitas na referida Constituição de 
1967, praticamente impondo uma nova Constituição Brasileira, embora mantidos a maioria dos seus dispositivos. ${ }^{19}$

Dentre as modificações impostas, destaca-se o Ato Institucional $n^{\circ}$. 5, de 13 de dezembro de 1968, que alterou substancialmente os direitos políticos dos cidadãos brasileiros, pela transferência ao Presidente da República de poderes praticamente ilimitados, como decretar recesso do Poder Legislativo Nacional, Estadual e Municipal, suspensão dos direitos políticos, cassação de mandatos eletivos, com possibilidade de aplicação de medidas de segurança. $^{20}$

Com efeito, com os seguidos atos ditatoriais do Governo Militar, constata-se um enfraquecimento total da Cidadania Brasileira perante o Estado, com o fim da democracia no país, pelo fechamento do Congresso Nacional através do Ato Complementar nº 38, de 13 de dezembro de $1968^{21}$, suspensão das eleições para Prefeitos e Governadores, cassação de outros mandatos eletivos, suspensão de direitos políticos por até 10 (dez) anos.

Outrossim, malgrado apenas do ponto de vista formal, garantida "ampla defesa" aos acusados, nos termos do artigo 150, § 15, da retro-citada Constituição de 1967. Limitada a defesa judicial junto ao Poder Judiciário. Restringida a manifestação e qualquer forma de defesa social ou política, aos termos da lei, que praticamente passou a ser imposta através de decretos pelo Poder Executivo.

Também, são ampliadas as possibilidades de limitação das garantias individuais, como o direito de ir e vir durante o estado de sítio, embora mantido o habeas corpus sempre que alguém sofrer ou se achar ameaçado de sofrer violência ou coação em sua liberdade de locomoção, por ilegalidade ou abuso de poder. Nas transgressões disciplinares não caberá habeas corpus. Mantidas outras ações importantes, como o Mandado de Segurança e a Ação Popular. Assegurado o direito de representação e de petição aos Poderes Públicos, em defesa de direito ou contra abusos de autoridade, malgrado com pouco resultado na prática, pela falta de respeito aos direitos em geral.

\footnotetext{
19 Idem, p. 9, que apresenta os considerandos da Emenda Constitucional $\mathrm{n}^{\mathrm{o}}$. 1, de 17 de outubro de 1969, inclusive, que a Constituição de 24 de janeiro de 1967 deveria ser mantida, continuando inalterados os dispositivos indicados.

20 Idem, p. 201.

21 Idem, p. 203.
} 


\section{Direito Constitucional da Cidadania Brasileira na Constituição de 1969}

Pela Emenda Constitucional $n^{\circ} 1$, de 17 de outubro de 1969, que deu nova forma à Constituição de 1967, embora tenha mantida a maior parte de seus dispositivos, também observa-se uma desvalorização do conceito de cidadania por sua substituição pelo o de nacionalidade (art. 145), com limitação inclusive dos direitos políticos, especialmente pela imposição dos Atos Institucionais e Complementares.

Com relação aos Direitos e Garantias Individuais (art. 153), assim como ocorria com os Direitos Políticos, teoricamente, constata-se a manutenção dos consagrados nas Constituições anteriores, sem considerá-los, claramente, direitos de(a) cidadania, com algumas restrições, especialmente, na prática, com relação ao direito de reunião, associação, manifestação do pensamento, protegido apenas ao final do texto.

Pelo artigo 153, caput, a Constituição assegura aos brasileiros e aos estrangeiros residentes no País a inviolabilidade dos direitos concernentes à vida, à liberdade, à segurança e à propriedade, nos termos dos incisos seguintes, como todos são iguais perante à lei, ninguém será obrigado a fazer ou deixar de fazer alguma coisa senão em virtude de lei e a lei não prejudicará o direito adquirido, o ato jurídico perfeito e a coisa julgada, enfim, garantidos formalmente os direitos civis básicos.

Com efeito, embora assegurada ao paciente ampla defesa, poderia ser declarada a perda ou a suspensão dos seus direitos políticos, inclusive, por decretação do Presidente da República (art. 149, § $1^{\circ}$ ), além dos casos por decisão judicial.

Relativamente aos direitos sociais, também praticamente não se observa mudança substancial, especialmente do ponto de vista da cidadania, continuando a considerá-los direitos dos trabalhadores (art. 165), com alguma modificação, como passando a educação ser considerada direito de todos e dever do Estado (art. 176).

Em resumo, os direitos da Cidadania na citada Constituição Brasileira de 1969, teoricamente, resumiam-se aos direitos políticos, com manutenção dos direitos e garantias individuais e os sociais aos brasileiros enquanto indivíduos, sem qualquer concepção de cidadania, que foram muito mais restringidos, na prática, em especial, pelos Atos Institucionais e Complementares. 
Com efeito, malgrado apenas do ponto de vista formal, assegurando aos acusados "ampla defesa", nos termos do artigo 153, § 15, da retro-citada Constituição de 1969. Limitada a defesa judicial junto ao Poder Judiciário. Restringida a manifestação e qualquer forma de defesa social ou política, aos termos da lei, que praticamente passou a ser imposta através de decretos pelo Poder Executivo.

Também, são ampliadas as possibilidades de limitação das garantias individuais, como o direito de ir e vir durante o estado de sítio, embora mantido o habeas corpus sempre que alguém sofrer ou se achar ameaçado de sofrer violência ou coação em sua liberdade de locomoção, por ilegalidade ou abuso de poder. Nas transgressões disciplinares não caberá habeas corpus. Mantidas outras ações importantes, como o Mandado de Segurança e a Ação Popular. Assegurado o direito de representação e de petição aos Poderes Públicos, em defesa de direito ou contra abusos de autoridade, malgrado com pouco resultado na prática, pela falta de respeito aos direitos em geral.

Ademais, com os Atos Complementares e os Atos Institucionais posteriores, na prática, os direitos civis, políticos e sociais, mesmo os protegidos aos brasileiros na condição de apenas indivíduos, foram ainda mais restringidos pelo regime militar.

Neste particular, importante ressaltar o fato do novo Código de Processo Civil Brasileiro, que entrou em vigor em 1974, ainda vigente, com inúmeras modificações, malgrado sem apresentar maiores resultados quanto à defesa da Cidadania local.

Consoante o Prof. Ernane Fidélis dos Santos,

o atual Código de Processo Civil prima, sobretudo, pelo esmero terminológico e pela coerência do sistema. O Autor do projeto foi o Prof. Alfredo Buzaid, então ministro da Justiça e as linhas mestras de sua inspiração fora a doutrina esposada pelo jurista italiano Enrico Tullio Liebman, que esteve exilado no Brasil durante a Segunda Guerra Mundial. ${ }^{22}$

Com efeito, o Prof. Edson Prata $^{23}$, após apresentar as principais inovações que o referido Código de Processo Civil Brasileiro teria apresentado, como a criação do procedimento sumaríssimo e a proibição de alguns expedientes protelatórios, termina por concluir que há imperfeições, como os inúmeros procedimentos especiais, regras e prazos

22 SANTOS, Ernane Fidélis. Manual de Direito Processual Civil. 15. ed. São Paulo: Saraiva, 2011. v. 1. p. 4.

23 PRATA, Edson. História do Processo Civil e sua projeção no direito moderno. Rio de Janeiro: Forense, 1987, p. 191-192. 
diferenciados, prazo diferenciado para o Ministério Público e outros órgãos, merecendo alguns reformas com vista a unificação dos procedimentos e a trazer maior celeridade da Justiça, na solução dos litígios.

Contudo, em que pesem os elogios ao retro-citado Código de Processo Civil, a verdade é que este considera as partes meramente como indivíduos, sem qualquer concepção de cidadania, estimula a demanda individual, em detrimento das ações coletivas ou difusas, enfim, prejudica a defesa dos direitos da Cidadania Brasileira.

\section{Conclusões finais}

Em resumo, com este aprofundamento de pesquisa e reflexão sobre a temática, podese concluir sobre a Evolução do Direito Constitucional da Cidadania Brasileira, até a Constituição Brasileira de 1969:

1. Durante o Brasil Colônia, mais especialmente até a Constituição de 1824, não há que se falar em direitos dos Cidadãos Brasileiros, haja vista que neste período não houve aqui Cidadania, nem Pátria Brasileira, mesmo porque, esta pressupõe a existência do EstadoNação, com território, governo e povo (Cidadania) próprios, o que somente ocorreu após a Proclamação da Independência.

2. Os direitos da Cidadania na Constituição Brasileira de 1824, refletindo já a Concepção Moderna de Proteção da Cidadania, consistiam na declaração de direitos políticos e civis, inclusive assim consagrados literalmente em declaração de direitos, malgrado com grande exclusão social, quanto a cor, sexo, idade e posse de bens econômicos, com possibilidade de serem suspensos.

3. Durante o Brasil Império, como reflexo dos Movimentos Sociais do final do Século XVIII, predominou a proteção material da Cidadania Brasileira, mediante a declaração de direitos civis e políticos, com a previsão de algumas ações judiciais e garantia de ampla defesa nos processos de natureza criminal.

4. A Constituição de 1891 praticamente manteve os mesmos direitos civis e políticos à Cidadania Brasileira, como na Carta anterior em forma de declaração, com alguma ampliação de seus titulares, pelo fim da escravidão, redução da idade mínima para ser eleitor, fim do voto censitário e indireto, malgrado continuando a exclusão política da mulher, dos mendigos, 
dos analfabetos e dos religiosos de forma geral. Prevalece a defesa dos direitos, através do Estado, por conta e risco do indivíduo.

5. Na Constituição Brasileira de 1934 observa-se um esvaziamento do conceito de cidadania, substituindo-o pelo de nacionalidade, com os direitos da Cidadania protegidos na forma de declaração, com igual consagração dos direitos políticos, e os direitos civis como garantias individuais, com incipiente garantia de direitos sociais.

6. Os direitos da Cidadania na Constituição Brasileira de 1937, voltaram a ser restritos aos direitos políticos, adotando concepção antiga de proteção da Cidadania, considerando cidadãos apenas os inscritos no alistamento eleitoral, com algumas garantias civis e sociais aos demais brasileiros como indivíduos e hipossuficientes, seguindo a concepção liberal de direito.

7. Na Constituição Brasileira de 1937, além de restringir os direitos do cidadão, esvaziou-se ainda mais o conceito de cidadania, o substituindo pelo de nacionalidade, o que dificultou a apropriação e a defesa dos direitos. Com efeito, embora mantidas algumas ações judiciais especiais, restringidos os poderes do Poder Judiciário e do Poder Legislativo, em detrimento da defesa da Cidadania Brasileira.

8. Na Constituição Brasileira de 1946, os direitos da Cidadania continuaram restritos aos direitos políticos, com manutenção dos direitos civis como garantias individuais, com alguma ampliação dos direitos sociais, com efeito, considerando os seus titulares como indivíduos hipossuficientes. Quanto à defesa da Cidadania Brasileira, não há praticamente alteração quanto à concepção de proteção anterior, garantindo "plena defesa" aos acusados, ainda que do ponto de vista formal, cabendo ao indivíduo a defesa dos seu próprio direito, mantendo o Estado eqüidistante, decorrente do princípio processual do dispositivo.

9. Pela Constituição Brasileira de 1967, mantida a substituição do conceito objetivo de cidadania pelo de nacionalidade, limitando os direitos dos cidadãos aos direitos políticos, com a proteção material dos direitos civis e sociais aos brasileiros como garantias individuais. Outrossim, ampliada a possibilidade de "ampla defesa" aos acusados, com a disposição de instrumentos administrativos e judiciais, ainda que do ponto de vista formal, em defesa dos direitos em geral.

10. Na Constituição Brasileira de 1969, a proteção legal material da Cidadania, praticamente, resumiam-se aos direitos políticos, com manutenção dos direitos e garantias individuais e os sociais aos brasileiros enquanto indivíduos, sem qualquer concepção de 
proteção da Cidadania, que foram muito mais restringidos, na prática, pelos Atos Institucionais e Complementares. Com efeito, quanto aos instrumentos de defesa, ainda que do ponto de vista formal, assegurado aos acusados "ampla defesa", nos termos do artigo 153, $\S$ 15, da retro-citada Constituição de 1969. Limitada a defesa judicial junto ao Poder Judiciário. Restringida a manifestação e qualquer forma de defesa social ou política, aos termos da lei, que praticamente passou a ser imposta através de decretos pelo Poder Executivo. $^{24}$

\title{
Evolution of the Constitutional Law of the Brazilian Citizenship
}

\begin{abstract}
Before the year of 1824, there was nothing to say about brazilian citizenship, as long as Brazil was Portugal's colony without administrative, political or social autonomy. There was no territory or people. In 1822, it was proclaimed the Independence of Brazil, specially with the Republic Constitution of 1824, when the Constitutional Law of Brazilian Citizenship started and evolved with the other Republican Constitutions of 1891, 1930, 1934, 1946, 1967 and 1969, according to what will be presented in this article. The Republic Constitution of 1988 will be depende in another paper.
\end{abstract}

Keywords: Citizenship. Constitutional. Right.

\section{REFERÊNCIAS}

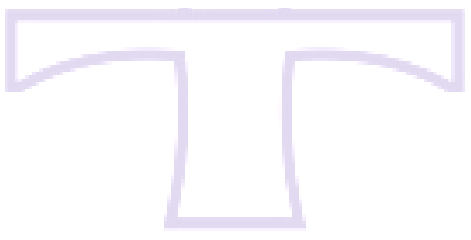

ALTAVILA, Jayme de. Origem dos direitos dos povos. 6. ed. São Paulo: Ícone, 1989.

BARACHO, José Alfredo de Oliveira. Teoria Geral da Cidadania: a plenitude da cidadania e as garantias constitucionais. São Paulo: Saraiva, 1995.

24 Através da Emenda Constitucional n ${ }^{\circ}$ 7, de 1977, foi inserido o $\S 4^{\circ}$, no art. 153, estabelecendo que não poderá excluir da apreciação do Poder Judiciário qualquer lesão de direito individual, o que denota a concepção individualista e liberal adotada, que considera cidadãos apenas os inscritos no órgão eleitoral, seus direitos limitados aos de natureza política, sendo os demais considerados apenas como indivíduos. Pela Emenda Constitucional nº 26/85, convocada Assembleia Nacional Constituinte, concluída em 1988. 
BARBALET, J. M. A cidadania. Lisboa: Estampa, 1989.

BARRETO, Vicente. Democracia, participação e cidadania. Revista Brasileira de Estudos Políticos, Belo Horizonte, v. 76, p. 141-145, jan. 1993.

BENEVIDES, Maria Victoria de Mesquita. A cidadania ativa. São Paulo: Ática, 1991.

BOBBIO, Norberto. A Era dos Direitos. Tradução Carlos Nelson Coutinho. Rio de Janeiro: Campus, 1991.

BORGES, Marcos Afonso. Evolução histórica do Direito Processual Civil. Revista da Faculdade de Direito da Universidade Federal de Uberlândia, Uberlândia, v. 17, p. 257 292, dez. 1988.

BUENO FILHO, Edgard Silveira. O direito à defesa na Constituição. São Paulo: Saraiva, 1994.

CAMPANHOLE, Adriano; CAMPANHOLE, Hilton Lobo. Constituições do Brasil. 4. ed. São Paulo: Atlas, 1986.

CANOTILHO, J. J. Direito Constitucional. 5. ed. Coimbra: Almedina, 1992.

CARVALHO, José Murilo de. Desenvolvimiento de la ciudadanía en Brasil. Ciudad de México: Fondo de Cultura Económica, 1995.

CAUBET, Christian G. As várias cidadanias da Constituição de 1988. Revista da Faculdade de Direito da Universidade Federal de Minas Gerais, Belo Horizonte, v. 32, n. 32, p. 221244, 1989.

DIÓGENES, Gloria. Direitos, cidadania e movimentos sociais. Nomos: Revista do Curso de Mestrado de Direito da UFC, Fortaleza, v. 11/12, n. 1/2, p. 115-123, jan./dez. 1992/1993.

FERREIRA, Nilda Teves. Cidadania: uma questão para a educação. Rio de Janeiro: Nova Fronteira, 1993.

FERREIRA FILHO, Manoel Gonçalves. Direitos Humanos Fundamentais. São Paulo: Saraiva, 1995. 
FIORILLO, Celso Antonio Pacheco. Os sindicatos e a defesa dos interesses difusos no Direito Processual Civil brasileiro. São Paulo: Revista dos Tribunais, 1995.

FIUZA, Ricardo Arnaldo Malheiros. Direito Constitucional comparado. 2. ed. Belo Horizonte: Del Rey, 1993.

GARCIA, Maria. Desobediência civil: direito fundamental. São Paulo: Revista dos Tribunais, 1994.

JHERING, Rudolf Von. A luta pelo Direito. Organização, Introdução e Notas de Fernando Luso Soares Filho. Lisboa: Cosmos, 1992.

KELSEN, Hans. Teoria Pura do Direito. Tradução João Baptista Machado. São Paulo: Martins Fontes, 1995.

LÚCIO, Alvaro Laborinho. O estado do cidadão. Revista Brasileira de Direito Comparado, Rio de Janeiro, n. 11, p. 102-110, jul. 1992.

MARSHALL, T. H. Cidadania, classe social e status. Tradução Meton Porto Gadelha. Rio de Janeiro: Zahar, 1967.

MARQUES, José Frederico. Manual de Direito Procesual Civil. 2. ed. São Paulo: Saraiva, 1974.

MAZZILLI, Hugo Nigro. A defesa dos interesses difusos em juízo. 4. ed. São Paulo: Revista dos Tribunais, 1993.

MOISÉS, José Álvaro. Cidadania e participação. São Paulo: CEDEC, 1990.

MONTESQUIEU. O espírito das leis. Tradução Pedro Vieira Mota. São Paulo: Saraiva, 1995.

NERY JUNIOR, Nelson. Princípios do Processo Civil na Constituição Federal. 5. ed. São Paulo: Revista dos Tribunais, 1999.

NOGUEIRA, Paulo Lúcio. Instrumentos de tutela e direitos constitucionais. São Paulo: Saraiva, 1994. 
PASSOS, J. J. Calmon de. Cidadania tutelada. Revista de Processo, São Paulo, ano 18, n. 72, p. 124-143, out./dez. 1996.

PEREIRA JUNIOR, Jessé Torres. O direito à defesa na Constituição de 1988. Rio de Janeiro: Renovar, 1991.

PRATA, Edson. História do Processo Civil e sua projeção no direito moderno. Rio de Janeiro: Forense, 1987.

QUIRINO, Célia Galvão; MONTES, Maria Lúcia. Constituições brasileiras e cidadania. São Paulo: Ática, 1987.

ROCHE, Maurice. Rethinking citizenship. Cambridge: Polity Press, 1992.

SALES, Teresa. Caminhos da cidadania. Revista Associação Brasileira de Reforma Agrária-ABRA, v. 23, n. 2, p. 45-57, maio/ago. 1993.

SANTOS, Ernane Fidélis. Manual de Direito Processual Civil. 15. ed. São Paulo: Saraiva, 2011. v. 1.

SANTOS, Moacyr Amaral. Primeiras Linhas de Direito Processual Civil. 14. ed. São Paulo: Saraiva,1990.

SARAIVA, Paulo Lobo. Garantia Constitucional dos Direitos Sociais no Brasil. Rio de Janeiro: Forense, 1983.

SILVA, José Afonso. Curso de Direito Constitucional Positivo. 9. ed. São Paulo: Malheiros, 1993.

SILVA PINTO, Márcio Alexandre da. Evolução Histórica do Direito Processual. 1991. Trabalho de Conclusão de Curso (Especialização)-Universidade Federal de Uberlândia, Uberlândia, 1991.

SILVA PINTO, Márcio Alexandre da. Direitos Sociais de(a) Cidadania. 1997. Dissertação (Mestrado)-Pontifícia Universidade Católica de São Paulo, São Paulo, 1997.

SILVA PINTO, Márcio Alexandre da. Evolução do Direito Público da Cidadania. Revista da Faculdade de Direito da Universidade Federal de Uberlândia, Uberlândia, v. 34, p. 201250, dez. 2006. 
SILVEIRA, José Néri. Em busca da plenitude da cidadania. Revista dos Tribunais, São Paulo, v. 82, n. 687, p. 236-242, jan. 1993.

SILVEIRA, Paulo Fernando. Devido processo legal: due process of law. Belo Horizonte: Del Rey, 1996.

SOUZA, Herbet de; RODRIGUES, Carla. Ética e cidadania. São Paulo: Moderna, 1994.

SOUZA, Luiz Sérgio Fernandes. O papel da ideologia no preenchimento das lacunas no direito. São Paulo: Revista dos Tribunais, 1993.

SPINK, Mary Jane Paris et al. A cidadania em construção. São Paulo: Cortez, 1994.

TEIXEIRA, Sálvio de Figueiredo et al. As garantias do cidadão na Justiça. São Paulo: Saraiva, 1993.

TELLES JUNIOR, Goffredo. O povo e o poder. São Paulo: Malheiros, 2003.

THEODORO JÚNIOR, Humberto. Curso de Direito Processual Civil. Rio de Janeiro: Forense, 1990.

TOURINHO, Arx. Filiação partidária, cidadania e ministério público. Revista da Procuradoria Geral da República, Brasília, n. 8, p. 180-187, jan./jun. 1995.

Recebido: maio/2015. Aprovado: fevereiro/2016 